ESPAÇO TEMÁTICO: VIOLÊNCIA, SAÚDE E CLASSES SOCIAIS

\title{
Desafios à política de saúde brasileira: impactos no direito ao aborto legal
}

\author{
Jayce Mayara Mendes Medeiros ${ }^{1}$ \\ https://orcid.org/0000-0001-8446-0984
}

${ }^{1}$ Universidade Federal de Pernambuco, Departamento de Serviço Social, Programa de Pós - Graduação em Serviço Social, Recife, PE, Brasil

\section{Desafios à política de saúde brasileira: impactos no direito ao aborto legal}

Resumo: Apesar do aborto não ser criminalizado no Brasil em três situações específicas: em decorrência do estupro, risco de morte materna e fetos anencéfalos; e de estar previsto que a assistência ao abortamento nessas situações devem ocorrer nos serviços públicos de saúde, ainda são muitas as barreiras para a concretização desse direito, seja pelos fatores morais e religiosos dos profissionais de saúde, seja pela própria precarização do Sistema Único de Saúde (SUS) que apresenta colapsado diante das inúmeras demandas e escassos investimentos. Dessa forma, neste artigo pretende-se sintetizar os principais desafios ao Sistema Único de Saúde e os impactos na assistência ao aborto previsto em lei, mais precisamente àquele proveniente de violência sexual.

Palavras-chave: Sistema Único de Saúde. Aborto. Violência Sexual.

\section{Challehnges to Brazilian health policy: impacts on the right to legal abortion}

Abstract: Although abortion is not criminalized in Brazil in three specific situations: as a result of rape, risk of maternal death and anencephalic fetuses; and it is foreseen that abortion assistance in these situations should occur in public health services there arestill many barriers to the realization of this right, either due to the moral and religious factors of health professionals, or due to the precarious Unified Health System (SUS) Which is collapsed in the face of numerous demands and scarce investments. Thus, this article intends to summarize the main challenges to the Unified Health System (SUS) and the impacts on abortion assistance provided by law, more precisely to those from sexual violence.

Keywords: Unified Health System. Abortion. Sexual Violence.

Recebido em 14.07.2020. Aprovado em 15.12.2020. Revisado em 25.01.2021.

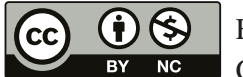

Este é um artigo publicado em acesso aberto (Open Access) sob a licença Creative Commons Attribution NonCommercial, que permite uso, distribuição e reprodução em qualquer meio, sem restrições desde que sem fins comerciais e que o trabalho original seja corretamente citado. 


\section{Introdução}

O aborto no Brasil é criminalizado desde o Código Penal de 1940, com apenas duas exceções: em casos de estupro e risco iminente de morte materna. Em 2012, após várias pressões dos movimentos feministas e da saúde pública, o Supremo Tribunal Federal (STF) decidiu pela legalidade do aborto também nos casos de anencefalia.

Apesar disso é relativamente recente a normatização de políticas direcionadas ao estabelecimento de diretrizes e princípios para o atendimento, no âmbito do Sistema Único de Saúde (SUS), das mulheres vítimas de violência sexual, que recorrem à prática do abortamento. Tais normativas estão concentradas nos serviços públicos de saúde e obtiveram maior ênfase a partir dos anos 2000.

No entanto, o direito ao aborto nessa situação sempre apresentou grandes resistências para sua efetiva implementação. Várias são as motivações disso: a) questões de ordem moral e religiosa que estão enraizadas no funcionamento das instituições e no comportamento dos profissionais; b) a precarização e superlotação dos serviços públicos de saúde, que ocasiona a secundarização e minimização dessa demanda; c) a crescente privatização dos serviços públicos de saúde, que também impacta na qualidade dos serviços prestados e na cisão dos princípios e diretrizes do Sistema Único de Saúde, conquistado através de grandes lutas sociais; d) o aumento do conservadorismo, intensificado e fortalecido após o golpe de $2016^{1}$ e a eleição de Jair Bolsonaro.

Tais tendências, principalmente esta última, vem demonstrando que vários direitos sociais historicamente conquistados estão sendo aniquilados sem, contudo, necessitar de uma mudança constitucional. O que tem se evidenciado é, na verdade, um profundo desrespeito aos princípios constitucionais e às legislações que, por algum tempo, representaram a incorporação de demandas dos movimentos sociais.

No tocante aos direitos do público feminino, esses sempre foram reconhecidos mais tardiamente e efetivados com maiores dificuldades. Isso se explica, em parte, pela predominância do patriarcado, presente na formação social e histórica do Brasil e que se reproduz até os dias atuais sob diversas expressões.

Verifica-se que, no contexto atual, além das inflexões do patriarcado, os direitos das mulheres, sobretudo os direitos sexuais e reprodutivos, estão sendo cada vez mais subjugados a partir da intensificação do conservadorismo, expressos nos discursos morais e religiosos que passam a interferir mais fortemente no âmbito das políticas públicas.

Procura-se a partir deste artigo: a) caracterizar os avanços obtidos no âmbito da saúde sexual e reprodutiva das mulheres; b) analisar os atuais desafios para a concretização do direito ao abortamento, tomando como base a mercantilização e sucateamento crescente dos serviços públicos de saúde, o desrespeito constante aos princípios do SUS e às normas constitucionais, assim como o aprofundamento dos ataques aos direitos das mulheres, sobretudo quanto à autonomia de seus corpos.

$\mathrm{O}$ artigo está dividido em três partes. A primeira está destinada a trazer reflexões gerais sobre o desenvolvimento da política de saúde no Brasil e os atuais desafios diante da crescente privatização do setor. Na segunda parte pretende-se analisar como a assistência às mulheres que optam pelo abortamento, após estupro, se desenvolveu no País. E na terceira e última parte pretende-se indicar algumas tendências e desafios para a concretização deste direito no atual contexto de aumento do conservadorismo.

\section{A política de saúde no Brasil e os limites para sua concretização diante dos ataques privatistas}

A política de saúde no Brasil foi construída em um contexto de grande efervescência política, tendo como pano de fundo a luta pela redemocratização. Naquele período foram evidenciadas várias lutas por direitos sociais, pela garantia de políticas públicas universais, por direitos à liberdade de expressão, pela construção de uma concepção de seguridade social e pelo estabelecimento de uma nova Constituição Federal.

No âmbito da saúde teve grande destaque o movimento pela reforma sanitária, que reunia profissionais de saúde, usuários e outros setores da sociedade. A partir desse importante movimento foi possível pensar a construção de um sistema único responsável pelo atendimento universal e de forma integral a todos os cidadãos; a concepção ampliada de saúde, bem como a defesa de que a política de saúde deve ser responsabilidade do Estado e direito de todo cidadão, sem discriminação de qualquer ordem. 
O Sistema Único de Saúde (SUS) foi previsto na Constituição Federal (1988), nos artigos 196 a 200 , e consolidado pela Lei $n^{\circ}$ 8.080/1990 e Lei $n^{\circ}$ 8.142/1990 (BRASIL, 1990a, b). Estas legislações contêm a previsão de que o SUS é um sistema público descentralizado, com comando único em cada esfera de governo, uma rede regionalizada e hierarquizada de serviços, conforme a complexidade de atenção à saúde, de acesso universal, com integralidade da atenção, financiamento tripartite e o controle social (CORREIA, 2015, p. 70-71).

A conquista do SUS, contudo, não ocorreu sem grandes disputas com os setores privatistas da sociedade. Sabe-se que a saúde, principalmente durante o período de vigência da ditadura militar, foi alvo constante do mercado privado e utilizado como estratégia de desenvolvimento dos setores capitalistas, através da utilização do fundo público.

Tais setores continuaram a disputar o financiamento da saúde pública, tanto que na própria Lei nº 8.080/1990 conseguiram implementar o artigo que torna possível a participação da iniciativa privada no âmbito do SUS, em caráter complementar ${ }^{2}$ (BRASIL, 1990a). Correia (2015) sinaliza que na época a justificativa utilizada era a de que inicialmente o SUS não teria como abarcar toda a demanda do País, tendo em vista que estaria em processo de consolidação. A perspectiva era de que, a partir do seu fortalecimento, fosse realizado um processo periódico de estatização do sistema público de saúde.

No entanto, o que se evidenciou foi diferente: ao invés da progressiva estatização da saúde o que tem ocorrido é uma progressiva privatização (CORREIA, 2015), fato que está diretamente articulado aos empecilhos para a consolidação do SUS na atualidade.

O interesse dos setores privatistas no âmbito da saúde — assim como no conjunto de políticas sociais consideradas rentáveis ao capital — faz parte da constituição do modo de produção capitalista, cujo principal objetivo é a acumulação de riquezas por uma classe minoritária e dominante que atua, inclusive, no aparelho estatal. Dessa forma, a política de saúde situa-se no cenário de disputa de projetos societários, determinada por uma totalidade concreta (COSTA; MÉLLO; NOGUEIRA, 2018).

Ao longo do desenvolvimento do sistema capitalista foram estabelecidas diversas estratégias de supremacia do poder dominante e sua acumulação. Durante a promulgação da Constituição Federal de 1988 e as legislações referentes à saúde pública, já se consolidava nos países de capitalismo central o neoliberalismo. O modelo neoliberal foi responsável pelo acirramento do sistema de exploração e opressão próprios à dinâmica da sociedade capitalista. Sua principal função foi operar contrariamente aos direitos sociais conquistados, à regulamentação do trabalho e na demonização do Estado no que se refere à atuação no campo social, tornando sua ação focalizada e seletiva aos setores mais pauperizados da sociedade, quebrando, assim, qualquer concepção universal de políticas sociais.

Segundo Harvey (2007, p. 03):

A criação desse sistema neoliberal implicou muita destruição, não somente para as estruturas e poderes institucionais, mas também sobre as relações estruturais da força de trabalho, relações sociais, nas políticas de bem-estar social, nos arranjos tecnológicos, modos de vida, pertencimento à terra, hábitos afetivos, modos de pensar e outros mais.

Em países como o Brasil com larga tradição autoritária e tímido histórico no âmbito da garantia e respeito aos direitos sociais, a retórica neoliberal encontrou terreno fértil. A partir da concepção ideológica de que a crise ocorre pelos altos custos com os gastos em direitos sociais, os primeiros ataques foram direcionados a este âmbito, através da defesa do enxugamento dos gastos públicos estatais e do estímulo à compra de necessidades básicas: saúde, educação, entre outros. Essa é, inclusive, uma das máximas retóricas do modelo neoliberal: a de estimular respostas individuais/privatistas para questões que são de ordem coletiva.

No que se refere à política de saúde verifica-se o sucateamento cada vez maior dos serviços públicos, ao passo que aumenta a demanda pelos planos privados de saúde. De acordo com Soares (2010, p. 49), nessa lógica,

quanto mais o SUS é precarizado, mais cresce o mercado de serviços privados e, não por acaso, na década de 90, esse mercado se amplia consideravelmente, tanto que em 2000 é criada a Agência Nacional de Saúde Suplementar (ANS), que passa a ser responsável pela regulação, controle e fiscalização dos serviços de saúde suplementar.

Nesta mesma linha de raciocínio, as autoras Costa, Méllo e Nogueira (2018, p. 1100) afirmam que: 
Esse setor suplementar tem como um de seus objetivos a ampliação do mercado de planos e seguros privados de saúde, e vem conformando um processo de consolidação de um sistema de saúde dual no país, confrontando a lógica da assistência médica como uma mercadoria ou um produto à lógica do SUS, baseada na noção de direito de cidadania.

Outra tendência de estímulo à privatização é a utilização de repasses financeiros para as organizações e fundações sociais, a fim de executarem as ações e serviços públicos de saúde. Tal estratégia faz parte do modelo gerencial do Estado, amplamente defendido e implementado no governo de Fernando Henrique Cardoso (1995-2003), com forte orientação e apoio do Banco Mundial.

Para Ximenes, Schmaller e Bezerra (2018, p. 118), as Organizações Sociais da Saúde (OSS) são estratégias do capital, consequentemente, uma tendência mundial de substituir o papel executor do Estado.

No Brasil, a materialização da referida contrarreforma foi realizada no governo de Fernando Henrique Cardoso, a partir de 1995, com a criação do Ministério da Administração Federal e Reforma do Estado (MARE), dirigido pelo então Ministro Luiz Carlos Bresser Pereira, que comandou a equipe formuladora do Plano Diretor da Reforma do Estado (PDRE) e dos cadernos do MARE, que consta de uma série de documentos que buscavam justificar as reformas do Estado. Esse plano tinha como princípio de que as funções do Estado deveriam ser de coordenar e financiar as políticas públicas, e não, de executá-las, transferindo a execução destas para o setor "público não-estatal" que, na realidade, é regido pela lógica do privado. Nesse Plano Diretor, através do denominado programa de "publicização", foi proposto o repasse de serviços, antes de responsabilidade do Estado, para "entidades de direito privado" executálos, mediante o repasse de recursos públicos (CORREIA, 2015, p. 79).

Dessa forma, "desde a década de 1990, assistimos ao processo de universalização excludente em que o mercado privado de saúde tem se expandido com o apoio do Estado" (CORREIA, 2015, p. 74). Verifica-se, porém, que com o aprofundamento do Estado neoliberal no Brasil, vários ataques foram e estão sendo realizados aos princípios do SUS, principalmente no que se refere à universalidade da assistência e à responsabilidade do Estado. Mesmo nos governos tidos como democráticos populares — como do Presidente Luiz Inácio Lula da Silva (2003-2011) e Dilma Rousseff (2011-2016) — a atuação dos setores privatistas na política de saúde não retrocedeu.

Os serviços de saúde tornaram-se cada vez mais espaços de supercapitalização e relevante fonte de maximização do capital. As diversas formas do capital, em tempos de dominância financeira, conectam a cadeia de mercadorias e serviços desde o espaço da produção e comercialização até as finanças: indústrias de medicamentos e equipamentos médico-hospitalares, sistema público de saúde, redes de hospitais, clínicas, farmácias, planos privados de saúde, seguros saúde, bolsas de valores, linhas de crédito e financiamento bancários, entre outros (SOARES, 2010, p. 42).

A autora chama a atenção para o fato de que todos esses ataques ao SUS passam sem qualquer mudança no seu marco legal, "de modo que o SUS materializado se realiza de forma cada vez mais distante do SUS legalmente instituído". (SOARES, 2010, p. 50).

A partir dessas análises é possível inferir que desde sua promulgação o SUS não conseguiu efetivar-se plenamente na sociedade brasileira. Assim como na totalidade da vida social e do conjunto das políticas sociais, a política de saúde apresenta-se como contradição e imbuída pelo contexto da luta de classes, ora com maior correlação de forças para a classe trabalhadora, ora para o capital.

É indiscutível, porém, os avanços obtidos a partir desse modelo universal de saúde — razão pela qual deve-se continuar sendo defendido. Dentre os avanços conquistados é válido pontuar as conquistas no âmbito dos direitos sexuais e reprodutivos, bem como da assistência às mulheres vítimas de violência, incluindo a assistência ao abortamento previsto em lei. 


\section{Assistência ao abortamento legal e seguro nas situações de violência sexual}

No Brasil, os avanços das políticas voltadas para as mulheres em situação de violência sexual estão intimamente relacionados ao movimento feminista, às lutas políticas pela redemocratização do país e ao movimento da reforma sanitária.

Nesse sentido, atrelado ao número cada vez maior de mulheres que recorriam aos serviços de saúde com histórico de agressões, principalmente no ambiente doméstico, foram consolidando-se concepções de que a violência contra a mulher precisava ser enfrentada pelo Estado com integração entre as diversas políticas públicas, não só as de caráter punitivo, mas também protetivo e preventivo, como a política de saúde.

Apesar de o direito ao abortamento estar previsto no Código Penal desde 1940, para as gestações decorrentes de estupro, devendo a mulher ser assistida nos serviços públicos de saúde, apenas em 1989 foi criado o primeiro serviço de saúde que ofertava assistência ao aborto legal. Trata-se do hospital de Jabaquara, criado na gestão da Prefeita Luiza Erundina (PT), em São Paulo.

Contudo, ainda não havia naquele período normatizações e orientações, bem como fluxos organizados nas estruturas dos serviços públicos de saúde para a assistência dessas mulheres de maneira integral e sistemática. Foi a partir desse contexto que o movimento feminista conseguiu ampla articulação com a Federação Brasileira de Ginecologia e Obstetrícia (FEBRASGO), possibilitando correlação de forças para o fortalecimento dessa discussão no Ministério da Saúde (MS).

É, portanto, no decorrer do desenvolvimento e da consolidação do Sistema Único de Saúde que foram elaborados documentos orientadores para os serviços e profissionais de saúde. Entre as normatizações elaboradas, destaca-se a "Norma técnica para Prevenção e tratamento de agravos resultantes da violência sexual contra mulheres e adolescentes", construído pelo Ministério da Saúde, em 1999, mas atualizada em 2005 (2 edição) (PORTELLA et al., [2005]) .

Neste documento é estabelecido como deve ocorrer todo o atendimento da mulher vítima de violência no SUS. Propõe que a assistência destinada a essa demanda seja garantida, preferencialmente, em local com estrutura e equipes próprias, longe das grandes maternidades e prontos-socorros como forma de garantir maior sigilo, privacidade e menos exposição da vítima. Trata também das orientações quanto à prevenção e tratamento das infecções sexualmente transmissíveis (PORTELLA et al., [2005]).

A versão mais atualizada dessa norma técnica (2005) estabelece ainda que a mulher não é obrigada a apresentar documento comprobatório da violência, como o boletim de ocorrência policial. Decisão embasada no Decreto-Lei n ${ }^{\circ}$ 2.848, de 7 de dezembro de 1940, art. 128, inciso II, do Código Penal (PORTELLA et al., [2005]).

Esta norma técnica é, sem dúvida, a mais importante normatização do MS quanto ao enfrentamento da violência no âmbito do SUS e à garantia do abortamento legal e seguro previsto em lei. Demarca, assim, que a interrupção gestacional em decorrência de violência sexual constitui um direito da mulher à plena garantia de sua saúde sexual e reprodutiva (PORTELLA et al., [2005]), além de representar sua autonomia perante decisões que impactam no seu corpo e na sua vida em sociedade.

Contudo, segundo Biroli (2018), essa Norma Técnica ao ser lançada enfrentou profundos questionamentos por parte, principalmente, dos setores religiosos. Contestava-se mais fortemente a dispensa de documentos comprobatórios sobre a violência. Como forma de responder a esses questionamentos foi lançada, em 2005, a Portaria $n^{\circ} 1.508 / 2005$, que dispõe sobre o procedimento de justificação e autorização da interrupção gestacional em decorrência de violência sexual (BRASIL, 2005). Essa Portaria foi importante para demarcar a responsabilidade do SUS na garantia de assistência às mulheres, além de estabelecer o fluxograma que os serviços de saúde devem adotar, perpassando pela escuta da mulher por equipes multiprofissionais capacitadas na temática, realização de exames e tipos de procedimentos clínicos que podem ser adotados para a prática do abortamento.

Após a consolidação dessas normatizações, várias unidades de saúde de todo o território nacional organizaram-se com o intuito de prestar assistência às mulheres vítimas de violência e ao abortamento previsto em lei. No entanto, são poucos os serviços de saúde que ofertam o aborto às mulheres em situação de violência sexual e muitos funcionam sem considerar as prerrogativas da norma técnica do Ministério da Saúde, como por exemplo, exigindo boletim de ocorrência ou autorização judicial para a realização do aborto. Além disso, ainda são muito presentes as barreiras de ordem moral e religiosa que impedem a concretização desse direito. 
Os desafios postos para a concretização do direito ao aborto são norteados, não só pelo atual estágio do desenvolvimento capitalista, que se contradiz com a universalização dos direitos sociais, mas também pelos elementos históricos, sociais e culturais que subjugam a mulher à opressão e violência.

A intensificação dos ataques aos direitos conquistados pelas mulheres não ocorre por acaso, mas porque historicamente a luta dos movimentos feministas questiona diretamente o próprio funcionamento da sociedade do capital e as bases que lhe dão sustentação, como o patriarcado. São lutas revolucionárias que transgridem a ordem do capital e, portanto, tornam-se ameaças para a manutenção da ordem.

Nesse sentido, a luta pelo direito ao aborto não se trata de um direito meramente liberal de decisão pelo próprio corpo, mas significa a defesa da autonomia das mulheres diante de um sistema marcadamente opressor que nos subjuga.

Nesse sentido, a afirmação da autonomia das mulheres para decidir sobre a interrupção de uma gestação é algo que toca em questões que não se restringem ao aborto, mas ao funcionamento da democracia, aos espaços e formas de regulação do Estado, "às hierarquias e formas toleráveis de dominação, aos direitos individuais e à relação entre todas essas questões e o princípio da laicidade do Estado" (BIROLI, 2014, p. 42).

\section{Os desafios contemporâneos no âmbito da saúde que impactam na concretização do direito ao abortamento}

$\mathrm{Na}$ conjuntura atual de aprofundamento dos preceitos neoliberais e de desrespeitos constitucionais, vários direitos sociais têm sido constantemente atacados e impedidos de se concretizarem. Sabe-se que a política neoliberal passou a direcionar as ações do Estado desde a década de 90, porém é a partir do golpe de 2016 que seus preceitos foram intensificados.

Vive-se a partir de então a aprovação da PEC 95, em 2016, durante gestão do presidente Michel Temer. Tal PEC prevê o congelamento de investimentos nas áreas estratégicas do sistema protetivo de direitos por vinte anos. Ou seja, se já era difícil a concretização dos princípios do SUS e das demais políticas que compõem o rol da seguridade social, a partir de então ficará ainda mais restrito o acesso dos sujeitos aos direitos essenciais, tais como saúde, educação, assistência social, previdência, moradia, entre outros (BRASIL, [2016]). Observa-se, assim, um verdadeiro colapso do sistema protetivo de seguridade social, construído a partir das lutas sociais.

Segundo Soares (2018, p. 26):

O conjunto dessa ofensiva vem se caracterizando como uma grande regressão civilizatória nos marcos da sociedade brasileira, configurando-se o que Marx denominou de expropriação da classe trabalhadora, precisamente sobre os direitos e as políticas sociais. Essa expropriação no âmbito do direito à saúde e da política de saúde atinge seu ápice a partir das alterações e proposições discutidas por Bravo, Pelaez e Pinheiro (2018): a aprovação da Emenda Constitucional 95, que institui o congelamento do teto dos gastos primários, impondo sobre o orçamento da saúde uma restrição que pode chegar a 640 bilhões, segundo estudo do IPEA (VIEIRA; BENEVIDES, 2016); a proposição dos Planos Populares de Saúde que está em vias de ser regulamentada; a proposição de alteração na lei que regulamenta os planos de saúde no Brasil, a alteração na Política Nacional de Atenção Básica em Saúde e as alterações na política de saúde mental, precisamente na Rede de Atenção Psicossocial, que retrocede em aspectos fundamentais à reforma psiquiátrica.

Além disso, a gestão presidencial de Jair Bolsonaro, iniciada em janeiro de 2019, aprofunda a devastação do SUS e de outras políticas sociais. Mesmo na conjuntura de pandemia, que se enfrenta no momento, não foi apresentado sequer um plano para frear o avanço da contaminação pelo novo coronavírus. Ao contrário, o que se instituiu como política governamental foi o negacionismo, o incentivo ao caos social e atitudes contrárias às orientações sanitárias de todo o mundo. O Brasil, portanto, é o único país que enfrenta uma pandemia sem um Ministro da saúde 4 .

O governo do Presidente Jair Bolsonaro avança, assim, na direção do aniquilamento dos direitos e de várias políticas sociais, dentre elas as voltadas para proteção das mulheres e outros grupos historicamente oprimidos, como negros/as, indígenas, quilombolas, homossexuais, entre outros. 
Além disso, a composição do governo atual é dividida entre duas principais alas que amedrontam a democracia e os direitos sociais: o setor militar e o fundamentalismo religioso. Sendo assim, os discursos morais e religiosos que muitas vezes travaram a concretude de diversos direitos sociais, incluindo os direitos sexuais e reprodutivos, ganham ainda mais solidez, sobretudo, por ganhar a legitimidade do Estado.

O que antes era discurso, vira política de Estado propriamente dita. O grande exemplo disso, foi a recente orientação do Estado para que houvesse a abstinência sexual durante o período carnavalesco (2020), como forma preventiva e de controle das infecções sexualmente transmissíveis. O que soa como cômico é na verdade a demonstração viva desse processo em curso de desmantelamento dos direitos das mulheres e da mínima autonomia já conquistada.

Outro exemplo gritante dessa interferência religiosa como política de Estado se apresentou através da proibição da educação sexual nas escolas, além da representação do Ministério da Mulher, da Família e dos Direitos Humanos: a religiosa Damares Regina Alves, cujo histórico de atuação é de posicionar-se contrária às políticas de assistência às mulheres em abortamento no País.

O Brasil caminha, assim, na direção do aprofundamento do conservadorismo, do rechaço aos direitos humanos, não apenas pela justificativa da necessidade de diminuição dos gastos sociais pelo Estado, mas também a partir das concepções ultraconservadoras, com forte apelo religioso e em defesa da formação tradicional da família: heterossexual, monogâmica e patriarcal.

É, portanto, na recusa aos direitos sexuais e reprodutivos que segmentos religiosos reacionários têm apostado quando se trata de construir as identidades político-eleitorais de seus representantes (BIROLI, 2018, p. 139-163).

\begin{abstract}
A defesa da "família cristã", que encarnaria arranjos convencionais numa perspectiva moral e econômica, tem sido o denominador comum nas ações correntes não apenas contra o direito ao aborto, mas também contra a união homoafetiva. "A ideologia de gênero", rubrica sob a qual os atores conservadores vêm reunindo movimentos sociais, agendas e políticas públicas que estejam em sua mira, tem servido para caricaturar os avanços e justificar a recusa de políticas para a igualdade de gênero e para a superação de preconceitos e violências.
\end{abstract}

De acordo com Löwy (2015), vários países têm vivenciado o ressurgimento da extrema direita, o que, em parte, pode ser explicado pelo processo de globalização capitalista neoliberal, formas religiosas de nacionalismo, além do alimento aos conflitos étnicos e confessionais. Para o autor, a crise econômica de 2008 contribuiu fortemente para esse processo, pois politicamente tal crise favoreceu muito mais a extrema direita, e suas ideias ultraconservadoras, do que os projetos da esquerda. "O sistema capitalista, sobretudo nos períodos de crise, produz e reproduz fenômenos como o fascismo, o racismo, os golpes de Estado e as ditaduras militares" (LÖWY, 2015, p. 663).

Toda essa conjuntura tem razão de ser. São estratégias de desenvolvimento do atual estágio do capitalismo, cujo maior objetivo é a apropriação cada vez maior do fundo público, ou seja, da riqueza socialmente produzida pela classe trabalhadora que, em tese, deveria reverter-se em serviços e direitos sociais em prol das necessidades básicas para sua reprodução social.

Tal conjuntura de ataque aos direitos sociais repercute não só na efetivação das políticas sociais estratégicas, como também na condição de vida da classe trabalhadora, em especial do público feminino. Isto porque a história das mulheres é marcada pela condição de inferioridade que nos foi atribuída nos diferentes modelos de sociedades já existentes.

Segundo Beauvoir (2016), a história da sociedade, assim como as leis, foi hegemonicamente escrita por homens, os quais ocupam lugar privilegiado de elaboradores legislativos e de outras funções e cargos que lhes conferem ainda mais poder perante o conjunto da sociedade, e em especial, sobre as mulheres. Tais leis ainda que reconheçam, em determinados períodos históricos, os direitos do público feminino, têm amplas dificuldades de concretização, devido, em parte, ao conceito ideológico ainda em vigor na sociedade, que legitima a subalternização da condição feminina.

Quanto às dificuldades existentes para a efetivação do direito ao aborto legal, sabe-se que, mesmo após diversas normatizações, este tema sempre foi alvo de resistência dos profissionais de saúde e da sociedade como um todo, que tende a analisar a prática do aborto sob um prisma religioso e moralizante. 
Mas, para além disso, verifica-se que ainda são insuficientes os serviços de referência para o atendimento integral das mulheres vítimas de violência sexual e que realizam também a prática do aborto. Ainda há incipiente preparo dos profissionais de saúde sobre esta temática, os quais insistem em conectar a violência apenas ao âmbito policial, e não como um determinante social da saúde.

A esse respeito, em 2015, Madeiro e Diniz (2016) publicaram uma pesquisa que identificou 68 serviços de saúde no Brasil destinados a esta finalidade. No entanto, destas unidades, apenas 37 realizavam o abortamento em decorrência do estupro.

Já naquele período, a pesquisa evidenciou que entre as dificuldades encontradas no cotidiano dos serviços estão duas principais: 1 - Pequena disponibilidade de profissionais, principalmente médicos, para realização do aborto; 2 - Muitos desses profissionais apresentam barreiras morais e religiosas; 3 - Necessidade de maior capacitação da equipe quanto à ampliação do conhecimento sobre a legislação e sobre a garantia de direitos em saúde sexual e reprodutiva (MADEIRO; DINIZ, 2016).

Embora o direito ao aborto ainda seja restrito no Brasil sua prática é uma realidade. Muitas mulheres recorrem a este método, muitas vezes de maneira clandestina, pondo em risco suas vidas. De acordo com a pesquisa nacional de Aborto, quase 01 em cada 05 mulheres brasileiras aos 40 anos já realizou pelo menos um aborto. Em 2015 foram 416 mulheres que recorreram a tal prática. Cerca da metade precisou ser internada após procedimento, na maioria, clandestinos. O estudo concluiu que em 2015 ocorreram meio milhão de abortos no Brasil. (DINIZ; MEDEIROS; MADERO, 2016, p. 659).

Ou seja, o aborto já é uma realidade no País. O que precisa ser defendido é que, amparado pela defesa da democracia e emancipação das mulheres, o Estado garanta a assistência necessária para que elas não tenham suas vidas postas em risco. Foi nessa perspectiva que em 2018 grupos feministas e representações dos profissionais de saúde organizaram a audiência pública no Supremo Tribunal Federal (STF), cujo objetivo foi discutir a descriminalização do aborto no País até a $12^{\mathrm{a}}$ semana de gestação.

No entanto, tal audiência também contou com a participação de pessoas ligadas ao movimento intitulado pró-vida (contrários à prática do abortamento em qualquer circunstância, inclusive em casos de estupro). Evidenciando, assim, que o tema do aborto é alvo de fortes e constantes disputas político-ideológicas.

A prática do abortamento, sobretudo a clandestina, apresenta um claro recorte de classe e raça. Enquanto as mulheres de maior poder aquisitivo recorrem à prática em clínicas privadas, oferecendo um nível menor de insegurança - ainda que de forma clandestina —, as mulheres pobres recorrem a técnicas rudimentares, sem qualquer apoio e assistência clínica. Apresentam, portanto, maior risco de infecções e até morte, o que torna o aborto uma questão de saúde pública.

Segundo o Ministério da Saúde, o aborto é a quinta maior causa de mortalidade materna no País. Em 2016, dos 1.670 óbitos causados por problemas relacionados à gravidez ou ao parto, 127 foram devidos ao abortamento (FERNANDES, 2018). Percebe-se, assim, que a não garantia da assistência ao abortamento pelos serviços de saúde, somado à criminalização da prática, acarreta riscos à saúde das mulheres e complicações clínicas que sobrecarregam as unidades de saúde, culminando, inclusive, na morte dessas mulheres.

Somado a esses desafios, a crescente privatização dos serviços de saúde também interfere diretamente na assistência às mulheres vítimas de violência e, sobretudo, na prática do abortamento. Isso porque os serviços privados de saúde não seguem os princípios e diretrizes do SUS ${ }^{5}$, nem tampouco as normatizações do Ministério da Saúde quanto ao fluxograma para garantia de assistência dessas mulheres, não só nas situações de prevenção, como também em casos de aborto.

A crescente tendência de privatização por dentro do SUS, como a estratégia das fundações e organizações sociais para gerir os serviços públicos de saúde, também constitui um empecilho para real concretização do direito ao aborto. Muitas das instituições de saúde que passam a ser geridas por essas fundações são filantrópicas, portanto, com forte influência religiosa na sua estrutura e funcionamento, flexibilizando, assim, os princípios contidos no SUS em prol de preceitos religiosos.

Exemplo clássico dessa constatação ocorreu em Recife no ano de 2009, quando uma criança de nove anos foi impedida de realizar a interrupção gestacional que tinha direito, pois o Instituto Materno Infantil (IMIP) alegou inspirações religiosas contrárias ao procedimento. Houve, na ocasião, forte interferência do bispo da Igreja Católica que excomungou profissionais que se posicionaram em defesa da autonomia da criança. $\mathrm{O}$ procedimento foi realizado em uma instituição totalmente pública, o Centro Integrado de Saúde Amaury de Medeiros (CISAM). 
Sendo assim, se a privatização do SUS continuar sendo intensificada, como já se verifica como tendência, corre-se um sério risco de a assistência às mulheres ser ainda mais prejudicada. Isso significará maior exposição e violência às mulheres, podendo acarretar também no aumento da mortalidade feminina.

Dados do IPEA (2019) já sinalizam um aumento de 17\% da violência cometida contra as mulheres entre 2012 e 2017, havendo um prognóstico de escalada do feminicídio. Tais informações evidenciam os impactos do desmantelamento das políticas públicas de proteção à mulher (INSTITUTO DE PESQUISA ECONÔMICA APLICADA, 2019).

Corrobora-se com a análise de Soares (2018) que ao pontuar os ataques do governo Temer na política de saúde já sinalizava a desconstrução da concepção de direito público na saúde. Tais ataques estão sendo ainda mais incisivos no governo Bolsonaro que, se quer apresentou qualquer proposta de melhorias para o SUS, comprometendo-se, ao contrário, com o capital financeiro.

De acordo com a autora supracitada (2018, p. 29), não há dúvidas de que a inviabilização e/ou profunda restrição de alternativas emancipatórias - mesmo que sob os limites da cidadania burguesa - constitui-se o esteio para o aprofundamento da espoliação de bens e direitos públicos, precisamente o direito à saúde.

\section{Considerações finais}

Assiste-se, segundo Soares (2018, p. 29), a uma regressão civilizatória e a expropriação de direitos e políticas sociais com o objetivo de atualizar as necessidades de reprodução do capitalismo. A apropriação do fundo público, particularmente do fundo público da saúde, torna-se objeto de disputa dos grandes e pequenos conglomerados econômicos da saúde, inclusive internacionais — desde operadoras de planos de saúde, indústria farmacêutica, rede de farmácias, rede de hospitais etc.

O discurso reacionário está cada vez mais latente no Brasil que já apresentava raízes autoritárias e conservadoras. Historicamente são as mulheres que mais se veem atacadas com esses influxos, uma vez que já apresentam o direito à autonomia do seu corpo restrita pelas amarras impostas pelo patriarcado e agora refuncionalizadas pela defesa moral e religiosa.

Contudo, esses ataques não ocorrem sem a necessária resistência. Várias lutas contrárias às atuais propostas de aniquilamento dos direitos sociais têm ocorrido no País. Nesta conjuntura de quase aniquilamento dos direitos sociais se faz ainda mais necessária o fortalecimento dos movimentos sociais ligados à defesa da saúde pública universal e à luta pela emancipação das mulheres. A realidade continua em processo e em movimento, ao passo que as forças democráticas continuam tentando conquistar a hegemonia nesse embate de correlação de forças, que expressa a luta de classes.

\section{Referências}

BEAUVOIR, S. O segundo sexo: a experiência vivida. Rio de Janeiro: Nova Fronteira, 2016. v. 1 e 2.

BIROLI, F. Autonomia e Justiça no debate sobre o aborto. Revista Brasileira de Ciência Política, Brasília, n. 15, p. 37-68, set./dez. 2014. BIROLI, F. Gênero e desigualdades: limites da democracia no Brasil. São Paulo: Boitempo, 2018.

BRASIL. [Constituição (1988)]. Ementa Constitucional n 95, de 15 de dezembro de 2016. Altera o Ato das Disposições Constitucionais Transitórias, para instituir o Novo Regime Fiscal, e dá outras providências. Brasília, DF: Presidencial da República, [2016]. Disponível em: http://www.planalto.gov.br/ccivil_03/constituicao/emendas/emc/emc95.htm. Acesso em: 17 dez. 2020.

BRASIL. Lei n ${ }^{\circ}$ 8.080, de 19 de setembro de 1990. Dispõe sobre as condições para a promoção, proteção e recuperação da saúde, a organização e o funcionamento dos serviços correspondentes e dá outras providências. Brasília, DF: Presidência da República, 1990a. Disponível em: http://www.planalto.gov.br/ccivil_03/leis/18080.htm. Acesso em: 17 dez. 2020.

BRASIL. Lei no 8.142, de 28 de dezembro de 1990. Dispõe sobre a participação da comunidade na gestão do Sistema Único de Saúde (SUS) e sobre as transferências intergovernamentais de recursos financeiros na área da saúde e dá outras providências. Brasília, DF: Presidência da República, 1990b. Disponível em: http://www.planalto.gov.br/ccivil_03/leis/18142.htm. Acesso em: 17 dez. 2020.

BRASIL. Ministério da Saúde. Portaria n ${ }^{\circ} 1.508$, de $1^{\circ}$ de setembro de 2005. Dispõe sobre o Procedimento de Justificação e Autorização da Interrupção da Gravidez nos casos previstos em lei, no âmbito do Sistema Único de Saúde-SUS. Brasília: DF, Gabinete do Ministro, 1 set. 2005. Disponível em: https://bvsms.saude.gov.br/bvs/saudelegis/gm/2005/prt1508_01_09_2005.html. Acesso em: 17 dez. 2020. 
CORREIA, M. V. C. Entre a Reforma Sanitária e o SUS: os interesses do capital na saúde. In: CORREIA, M. V. C.; SANTOS, V. M. dos. (org.). Reforma Sanitária e contrarreforma na saúde: interesses do capital em curso. Maceió: EDUFAL, 2015.

COSTA, L. T. da C.; MÉLlO, L.; NOGUEIRA, P. T. A. Desenvolvimento do capitalismo no Brasil e as tendências da Política de Saúde. Revista Saúde e Sociedade, São Paulo. v. 27, p. 1094-1104, 2018.

DINIZ, D.; MEDEIROS, M.; MADEIRO, A. Pesquisa Nacional de Aborto 2016. Ciênc. saúde coletiva, Rio de Janeiro, v. 22, n. 2 , p. 653-660, fev. 2017. DOI 10.1590/1413-81232017222.23812016. Disponível em: https://www.scielo.br/pdf/csc/v22n2/1413-8123csc-22-02-0653.pdf. Acesso em: 17 dez. 2020.

FERNANDES, M. Aborto no Brasil: Como os números sobre abortos legais e clandestinos contribuem no debate da descriminalização. Agência Patrícia Falcão, [São Paulo], 31 jul. 2018. Disponível em: https://agenciapatriciagalvao.org.br/mulheres-de-olho/dsr/aborto-nobrasil-como-os-numeros-sobre-abortos-legais-e-clandestinos-contribuem-no-debate-da-descriminalizacao/. Acesso em: 17 dez. 2020 HARVEY, D. Neoliberalismo como destruição criativa. InterfacEHS: Revista de Gestão Integrada em Saúde do Trabalho e Meio Ambiente, São Paulo, v. 2, n. 4, Tradução, ago. 2007. Disponível em: http://www3.sp.senac.br/hotsites/blogs/InterfacEHS/wp-content/ uploads/2013/07/trad-2007.pdf. Acesso em: 18 dez. 2020.

INSTITUTO DE PESQUISA ECONÔMICA APLICADA (IPEA); FÓRUM BRASILEIRO DE SEGURANÇA PÚBLICA (FBSP). Atlas da Violência 2019. Brasília: Rio de Janeiro: São Paulo: IPEA; FBSP, 2019. Disponível em: http://www.forumseguranca.org.br/ wp-content/uploads/2019/06/Atlas-da-Violencia-2019_05jun_vers\%C3\%A3o-coletiva.pdf. Acesso em: 20 dez. 2020.

LÖWY, M. Conservadorismo e extrema-direita na Europa e no Brasil. Serviço Social \& Sociedade, São Paulo, n. 124, p. 652-664, out./dez. 2015. DOI https://doi.org/10.1590/0101-6628.044. Disponível em: https://www.scielo.br/pdf/sssoc/n124/0101-6628sssoc-124-0652.pdf. Acesso em: 10 dez. 2020.

MADEIRO, A. P.; DINIZ D. Serviço de Aborto Legal no Brasil: Um estudo nacional. Revista Ciência e Saúde Coletiva, v. 21, n. 2, 2016, p. 563-572. DOI 10.1590/1413-81232015212.10352015. Disponível em: https://www.scielo.br/pdf/csc/v21n2/1413-8123csc-21-02-0563.pdf. Acesso em: 17 dez. 2020.

PORTELLA, A. P. et al. Prevenção e tratamento dos agravos resultantes de violência sexual contra mulheres e adolescentes: normas técnicas. Brasília: Ministério da Saúde. Departamento de Políticas de Saúde. Departamento de Gestão de Políticas Estratégicas, [2005]. SOARES, R. C. A contrarreforma da política de saúde e o SUS hoje: impactos e demandas ao Serviço Social. 2010. 210 f. Tese (Doutorado em Serviço Social) -Faculdade de Serviço Social, Universidade Federal de Pernambuco. Recife, 2010. Disponível em: https://repositorio.ufpe.br/bitstream/123456789/9499/1/arquivo6539_1.pdf. Acesso em: 20 dez. 2020.

SOARES, R. C. Governo Temer e Contrarreforma na política de saúde: a inviabilização do SUS. Argumentum, Vitória, v. 10, n. 1, p. 24-000, jan/abr 2018.

XIMENES, A. F. SCHMALLER, V. P. V. BEZERRA, A. F. B. Alocação de Recursos do Fundo Público para Organizações Sociais da Saúde. Revista Sociedade em Debate, Pelotas. v. 24, n. 3, p. 113-128, set/dez 2018.

\section{Notas}

1 Apesar do termo jurídico ser impeachment, corrobora-se a análise política que tende a considerar este processo como um golpe, não contra uma presidenta ou partido político, mas contra o conjunto de direitos sociais e contra a classe trabalhadora, já que a partir desse golpe foram implementadas diversas políticas antidemocráticas.

2 Artigo $4^{\circ}$, inciso $2^{\circ}$ : A iniciativa privada poderá participar do Sistema Único de Saúde (SUS), em caráter complementar (BRASIL, 1990a).

3 A primeira edição dessa norma técnica é de 1999, que já tratava da temática do abortamento pelos serviços de saúde, quando a gravidez fosse decorrente de estupro. No entanto, contrariando o que determinava o código penal, era estabelecido que a mulher fizesse boletim de ocorrência sobre a violência como critério para a realização do abortamento (PORTELLA et al., [2005]).

4 No momento da preparação deste artigo, o Brasil estava há 60 dias sem Ministro da Saúde.

5 As próprias medicações para prevenção de infecções sexualmente transmissíveis pós-exposição só estão disponíveis nos serviços públicos de saúde.

\section{Jayce Mayara Mendes Medeiros}

mayaramendes.as@gmail.com

Mestrado em Serviço Social pelo Programa de Pós-graduação em Serviço Social da Universidade Federal de Pernambuco (UFPE) 


\section{(PPGSS/UFPE)}

Av. Prof. Moraes Rego, 1235 - Cidade Universitária

Recife - PE - Brasil

CEP:50670-901

\section{Agradecimentos}

Ao Programa de Pós-Graduação em Serviço Social/UFPE pelos conhecimentos proporcionados. À professora e orientadora Ana Cristina de Souza Vieira que me possibilitou refletir sobre as questões contidas nesse manuscrito, através da disciplina Política de Saúde e desafios contemporâneos. À Secretaria Estadual de Saúde de Pernambuco pelo incentivo e oportunidade de qualificação acadêmica e profissional. Agência financiadora

Não se aplica.

\section{Contribuições das autoras}

Não se aplica.

Aprovação por Comitê de Ética e consentimento para participação

Não se aplica.

Consentimento para publicação

Consentimento da autora.

Conflito de interesses

Não há conflito de interesses. 